\title{
MERCANTILIZAÇÃO DA AMAZÔNIA - DIREITO E POLÍTICA EXTERNA A SERVIÇO (?) DA SUSTENTABILIDADE
}

\author{
THE MERCHANTABILITY OF THE AMAZON - LAW AND FOREIGN POLICY \\ AT THE SERVICE (?) OF SUSTAINABILITY
}

\author{
${ }^{1}$ Elany Almeida de Souza \\ ${ }^{2}$ Danielle Jacon Ayres Pinto
}

\section{RESUMO}

A sustentabilidade, de feições multidimensionais e inteligência sistêmica, reclama discussão alargada no âmbito da compreensão jurídica, tratamento específico e concatenado com a política externa em matéria ambiental. Buscam-se soluções negociadas que envolvem aspectos econômicos, políticos, tecnológicos e comportamentais, que encontram correlação com os diferenciais de poder e as assimetrias que marcam o sistema internacional. Importante analisar o processo ideológico de mercantilização pelo qual a Amazônia tem sido submetida e como o Direito e Política Externa podem atuar à serviço da Sustentabilidade. A pesquisa utilizou-se do método monográfico, por meio de pesquisa bibliográfica e documental, utilizando-se de uma abordagem dialética.

Palavras-chave: Mercantilização, Amazônia, Direito, Política externa, Sustentabilidade

\begin{abstract}
Sustainability, from multidimensional features and systemic intelligence, claims broad discussion within the legal understanding, specific treatment and concatenated with the external environmental policy. Are sought negotiated solutions involving economic, political, technological and behavioral aspects, which are correlated with the power differentials and the asymmetries that mark the international system. Important to analyze the ideological process of commodification in which Amazon has been submitted and how the Law and Foreign Policy can act in the service of sustainability. The research used the monographic method, through bibliographical and documentary research, using a dialectical approach.
\end{abstract}

Keywords: Merchantability, Amazon, Right, Foreign policy, Sustainability

\footnotetext{
${ }^{1}$ Mestranda em Direito pela Universidade Federal de Santa Maria - UFSM, Rio Grande do Sul (Brasil). E-mail: elanyalmeidas@gmail.com

${ }^{2}$ Doutora em Ciência Política pela Universidade Estadual de Campinas - UNICAMP, São Paulo (Brasil). Professora pela Universidade Federal de Santa Maria - UFSM, Rio Grande do Sul (Brasil). E-mail: djap2222@yahoo.com
} 


\section{INTRODUÇÃO}

O processo ideológico de mercantilização pelo qual a Amazônia tem sido submetida e as variáveis relevantes desse cenário, demonstram importante papel a ser desenvolvido pelo Direito e pela Política Externa à serviço da Sustentabilidade, de maneira a assegurar o direito inalienável ao futuro. Elementos geopolíticos, geoestratégicos, econômicos e sociais comprovam que a atual dinâmica social e o modo de produção adotado em escala global apontam para um processo de autodestruição.

Essa racionalidade adota o consumo como um fundamentalismo, onde a globalização impôs uma lógica capitalista, que sob um viés de perversidade e acompanhada pela finaceirização do capital, retirou o poder de decisão local para entregar nas mãos das grandes transnacionais e atores hegemônicos os interesses de comunidades locais e regionais, tanto no que respeitam às necessidades endógenas quanto exógenas de países da América Latina, África, entre outros.

Há em verdade, uma subjugação no que tangem às capacidades materiais de países considerados potências médias, como também aqueles que embora portadores de forças profundas (fatores geográficos, demográficos, econômicos, tecnológicos, ideológicos, político-jurídico, militar-estratégico) ainda não alcançaram equilíbrio na balança de poder. $\mathrm{O}$ globalitarismo, visto como um processo de totalitarismo, aponta a globalização e sua lógica perversa como único modelo e caminho a ser trilhado pelas políticas externas e internas dos países de todas as regiões do mundo.

Trata-se claramente do estabelecimento de uma interdependência complexa, ou seja, uma forma sutil de hierarquização do sistema internacional que não necessariamente decorre da imposição de projeção de poder por meio de forças militares, mas que dita apenas um caminho para o "progresso". Há, como dito, uma relação de hipossuficiência estabelecida com fins estratégicos de que uma determinada classe (âmbito social) e uma determinada região ou regiões (âmbito das relações internacionais) dê suporte à outras, seja por suas riquezas naturais ou pela sua força de trabalho.

Nesse cenário em que atuam protagonistas globais, as grandes potências, os países do Norte, e como coadjuvantes países do Sul, é flagrante uma distribuição geopolítica dos recursos naturais e do consumo global. De fato, é uma estratégia sócio econômica.

Nesse sentido, observa-se que até mesmo a concepção do grau de importância e consequentemente o Poder que cada ator exerce, é fruto de pensamentos socialmente 
naturalizados que são criados com a finalidade de edificação de um determinado processo hegemônico de organização social, ou seja, a natureza criada e a natureza transformada. Decorrência lógica dessa estratégia, são as distorções de discursos hegemônicos, as diferentes formas de mapeamento do mundo, a naturalização das fronteiras dentre outras arraigadas perspectivas não equânimes de realidade social e política.

Pretende-se, portanto, com o presente artigo analisar as varíaveis determinantes nesse contexto de mercantilização da Amazônia e como essa discussão se mostra socialmente relevante no atual contexto em que a América Latina, em especial o Brasil tem sido objeto de exploração de recursos naturais, seja pelos seus vastos mananciais de águas, caso das implantações de hidrelétricas, bem como por outros processos de mercantilização, como a exploração de xisto, nióbio entre outros.

Para fins de cumprir o objetivo, foi empregado o método monográfico, por meio de pesquisa bibliográfica e documental, e como técnicas foram utilizados fichamentos, resumos e coletas de notícias no âmbito da rede mundial de computadores. Como marco teórico, foram considerados os ensinamentos de Marilena Chauí, Layrarques, Juarez de Freitas, José Eli da Veiga, Maria Beatriz Oliveira da Silva, Sennes entre outros que enfrentam as variáveis determinantes do tema proposto.

Trata-se de uma abordagem dialética, onde em um primeiro plano será analisado o processo ideológico de mercantilização da Amazônia e, em um segundo momento, o papel do Direito e da Política Externa à serviço (?) da Sustentabilidade. Por derradeiro, em considerações finais, será demonstrada a urgência de se repensar e adotar novas epistemologias, isto é, uma outra racionalidade, que fuja do modelo da autodestruição, onde as formas de vida no mundo deixaram de ser o centro do mundo, e perderam lugar para o capital, onde a financeirização não foi só do capital, mas também da natureza e dos diversos modos de vida.

\section{1 - PROCESSO IDEOLÓGICO DE MERCANTILIZAÇÃO DA AMAZÔNIA.}

Analizar-se-á nos dois momentos que seguem, as variáveis dependentes e independentes nesse processo ideológico de mercantilização da amazônia e seus reflexos que resulta, ora em um discurso oficial da sustentabilidade, ora em oficioso. 


\subsection{Ideologia (antecedente) - varíavel independente $x$ mercantilização (consequente - variável dependente.}

Em matéria de ideologia e meio ambiente, é consabido que os dois conceitos caminham juntos na trilha de um discurso que vende o termo "sustentável" como imunizador das críticas de exploração da natureza e de seus recursos naturais pelo sistema capitalista.

Não tem sido diferente, o que ocorreu no contexto da implantação das hidrélétricas do Complexo do Madeira, Jirau e Santo Ântônio, ambas no Estado de Rondônia, bem como Belo Monte no Pará, não se podendo olvidar dos casos de exploração de xisto, nióbio entre outros, que revelam uma verdadeira manipulação ideológica a serviço da ciência e do mercado.

Nesse cenário, é a natureza e o homem que devem se adaptar ao sistema capitalista e não o inverso, se é que é possível falar-se em adaptação em um cenário de hegemonia constante. Nesse viés, torna-se claro o papel da ideologia, ora implantado por soft power em um cenário das relações de Estados internacionais, ora por uma espécie de ideologia interna que é fomentada pelos diversos meios de comunicação e interação social, dentre eles, a mídia, a escola enquanto ensino oficial e hegemônico, o modismo, a lei, a polícia, o Estado, entre outros instrumentos de alienação e reprodução de símbolos (LAYRARQUES, 2003, p. 53$55)$.

Esse discurso oficial que em verdade mascara o discurso oficioso, incute um pensamento de que a escolha mais acertada é a busca para a sustentabilidade do desenvolvimento capitalista. O desenvolvimento sustentável, é portanto, uma ideologia, a consciência de uma falsa realidade, na medida em que objetiva a manutenção da reprodução do capitalismo e sua consolidação global no controle da natureza enquanto recurso e a manutenção da pressão centro/periferia através da gestão dos recursos naturais dos países dependentes (OLIVEIRA, 2005).

A ideologia como mecanismo de dominação, senso comum, cristaliza o sistema posto, retira a possibilidade de crítica e cega para novas perspectivas, inclusive aquelas que não se restrigem a estatísticas econômicas e da proposital dinâmica da escassez. A praxis ambientalista demonstra que essa estratégia hegemônica que tem como instrumento a ideologia tem logrado êxito, sobretudo quando há uma transigência para com a ordem socioeconômica que contentando-se com o discurso oficial e as medidas "verdes" oferecidas, nada modificam o status quo, apenas o mantém (GARRAD, 2006, p. 32-37). 
Essa lógica de disputa entre ideologias hegemônicas e contra-hegemônicas demonstram que a questão ambiental não está imune aos embates ideológicos, pelo contrário, é quase que uma condição necessária, eis que a discussão acerca dos problemas ambientais não se reduzem a questões técnicas e comportamentais, mas são de fato questões políticas e ideológicas, porém na maioria das vezes a serviço da manutenção do status quo, restando por estimular reprodução e não a crítica ao sistema posto (LAYRARQUES, 2003, p. 35-36).

Esse processo de conscientização que vai de encontro a ideologia do sistema estabelecido, afasta o conformismo alienante e empodera a sociedade com fins de perceber a despolitização dos discursos e que as práticas em matéria ambiental restam por desembocar em discursos conciliatórios, ignorando a causa principal do problema. A reforma não é suficiente, necessário se faz a transformação da sociedade a partir do estímulo da visão crítica do sistema como um todo, onde uma educação ambiental seja capaz de resistir e emancipar.

A ideologia que indica o progresso técnico-científico como único caminho ao desenvolvimento, é, como afirma Marilena Chauí ao discorrer sobre o que é ideologia, uma forma de ocultamento da realidade social, isto é, separação da produção das ideias e das condições sociais e históricas nas quais são produzidas. É por intermédio da ideologia que “os homens legitimam as condições sociais de exploração e de dominação, fazendo com que pareçam verdadeiras e justas" (CHAUÍ, 1980, p. 8)

Essas idéias ou representações, no entanto, tenderão a esconder dos homens o modo real como suas relações sociais foram produzidas e a origem das formas sociais de exploração econômica e de dominação política. (CHAUÍ, 1980, p. 7-8)

Nas palavras de Chauí: “A ideologia é o processo pelo qual as idéias da classe dominante se tornam idéias de todas as classes sociais, se tornam idéias dominantes." (CHAUÍ, 1980, p. 35).

Vale citar ainda Marx, quando elucida que o processo de dominação pelo qual a ideologia é instrumento, invisibiliza a gênese das relações sociais e das formas sociais de dominação política, alienação e exploração econômica.

O capitalista não é capitalista por ser dirigente industrial, mas ele tem o comando industrial porque é capitalista. O comando supremo na indústria é atributo do capital, como no tempo feudal a direção da 
guerra e a administração da justiça eram atributos da propriedade da terra. (MARX, 2002, p.385-386)

Harvey, em Para entender o Capital, esclarece que:

As mudanças tecnológicas e organizacionais não são um deus ex machina, mas estão profundamente enraizadas na coevolução de nossa relação com a natureza, os processos de produção, as relações sociais, as concepções mentais de mundo e a reprodução da vida cotidiana. (HARVEY,2013, p. 228)

Necessário partir de uma análise das relações técnicas, demonstrando que são as relações sociais que transformam a relação genérica sociedade-natureza em uma relação histórica entre classes sociais. Ainda que as relações técnicas possuam certo grau de independência, o pólo das relações sociais é o atrativo que governa. (FOLADORI, 2001, p. 84)

Pensar o meio ambiente e o desenvolvimento sob a racionalidade cega do econômico, é reafirmar e reiterar a ideia de que não há liberdade, pois esses modelos impostos pela ideologia do capital, representam uma escravidão ao consumismo e à exploração da natureza, que se sobrepõe ao respeito à dignidade humana e a toda a complexidade que condiciona qualquer forma de vida no planeta terra.

A consciência ecológica não se realiza de forma isolada das condições sociais e é por isso que a proteção da natureza deve partir de uma transformação da sociedade. Sociedade esta que requer uma educação ambiental crítica, que não aceite a tese reducionista de que é a humanidade a deflagradora e vítima da crise ambiental, análise que não só atua na esfera moral (educação ambiental convencional), mas sim sob uma análise da esfera da política, pois identifica os sujeitos sociais específicos com níveis diferenciados de responsabilidade como de exposição e vulnerabilidade aos riscos ambientais, de modo inversamente proporcional ((LAYRARQUES, 2003, p. 56-58).

\subsection{A ideologia da sustentabilidade - entre o discurso oficial e o oficioso.}

A questão da sustentabilidade é outro ponto que pode ter tanto na ideologia quanto no Direito, fundamentos para a propagação de um discurso contra ou a favor do meio ambiente, por isso engloba variáveis diversas, dentre elas, senão a primeira, reside no que de 
fato consiste o termo em si. É inegável que a construção desse conceito ao longo da história perpassaram inúmeros elementos que são concebidos e sustentados conforme um certo discurso e para uma determinada finalidade.

Nesse sentido, o conceito sustentabilidade pode ser entendido conforme a finalidade para a qual está sendo adotada. É exatamente aí que mora o perigo, pois não buscar primeiro qual a essência e o que de fato esse termo busca representar, resulta em armadilhas que no mais das vezes se chocam com o seu fim precípuo.

Necessário, um caminho que sugere um novo conceito de desenvolvimento econômico, que afaste as ideias clássicas de que desenvolvimento significa necessariamente riqueza, progresso, exploração e lucro, ou seja, propõe "uma economia que não se imponha como predatória, mas que respeite o meio ambiente e o desenvolvimento sustentável”. Uma sustentabilidade que não seja diluída pela banalização do seu uso. Contudo, deve-se questionar se a ideia de crescimento econômico pode ser realmente compatibilizada à exigência de sustentabilidade; se a ideia de prosperidade leva em conta fenômenos como o aquecimento global e a erosão da biodiversidade (VEIGA, 2010, p. 7-14).

No tocante ao conceito de sustentabilidade, duas disciplinas ciêntíficas se destacam ao trabalhar o termo: a ecologia traz a lume o conceito de resiliência para melhor explicar o que é sustentabilidade, ou seja, ter a capacidade de enfrentar distúrbios, mantendo porém a estrutura. No âmbito da economia, esta se vale de indicadores, intensidade, se sustentabilidade fraca (cada geração deixe à seguinte, a somatória de três tipos de capital, que são considerados intercambiáveis e insubstituíveis: o propriamente dito, o natural-ecológico, e o humanosocial); ou sustentabilidade forte (obrigação de manter constantes os serviços do capitalnatural); e um terceiro vetor, a perspectiva biofísica (sustentabilidade só é possível com a minimização dos fluxos de energia e matéria que atravessam o subsistema, por isso defende a necessidade de desvincular os avanços sociais dos aumentos quantitativos da produção e do consumo). Independente de qual seja a linha a ser adotada, é fato que indicadores não serão capazes de medir o grau de sustentabilidade do processo econômico e o grau de qualidade de vida dele decorrente (VEIGA, 2010, p.7-21).

Para a corrente econômica convecional, o melhor caminho para a sustentabilidade é maximizar o crescimento econômico. Já na economia ecológica, para ter-se sustentabilidade necessário um regime em que a qualidade de vida de uma sociedade siga melhorando sem que necessariamente pressuponha expansão de seu subsistema econômico. Há ainda um terceiro caminho, o daqueles que acreditam na progressiva reconfiguração do processo produtivo, 
onde a oferta de bens e serviços ganharia eficiência, a economia continuaria a crescer sem que limites ecológicos fossem rompidos, ou que houvesse o esgotamento dos recursos naturais. A grande questão é romper com a macroeconomia centrada no consumo e não apenas esverdeála, uma macroeconomia que reconheça os limites naturais à expansão das atividades econômicas e rompa com a lógica social do consumismo (VEIGA, 2010, p. 21-26).

Poder-se-ia então falar em um pacto verde? Em verdade, reclama-se uma macroeconomia que rompa mentalmente com as elites políticas dos países centrais que tem como cerne único o aumento do consumo, para adotar uma macroeconomia da sustentabilidade, que reconheça os limites naturais à expansão das atividades econômicas, bem como se desconecte da lógica social do consumismo. Abandonar a visão de um sistema econômico fechado que não depende da biosfera, para passar a preocupar-se sim com as gerações futuras, trata-se da necessidade da transição a atividades econômicas sustentáveis, da redistribuição geopolítica da oferta e das demandas globais, onde os países mais avançados busquem uma planejada prosperidade sem crescimento, sendo esta a única forma de que as economias possam se tornar ambientalmente sustentáveis (VEIGA, 2010, p. 141-143).

Nesse diapasão, percebe-se que as variáveis ideologia (antecedente) e mercantilização (consequente) no contexto do meio ambiente $\mathrm{x}$ sustentabilidade, estão imbricadas e influenciam diretamente no processo pelo qual a Amazônia e seus recursos naturais tem sido submetidos. Cabe por conseguinte entender como as outras variáveis, Direito e Política Externa, podem ou não ser instrumentos à serviço da sustentabilidade.

\section{2 - DIREITO E POLÍTICA EXTERNA À SERVIÇO (?) DA SUSTENTABILIDADE.}

De igual modo, far-se-á a análise dos papéis do Direito e da Política Externa enquanto variáveis dependentes e independentes e seus reflexos na busca da sustentabilidade ambiental.

\subsection{Direito (antecedente) - varíavel independente $x$ sustentabilidade (consequente) - variável dependente.}

O que se questiona nesse momento é, até que ponto o Direito tem sido de fato um instrumento a serviço da sustentabilidade ambiental no que toca ao processo de mercantilização pela qual os recursos naturais, em específico da Amazônia, tem sido objeto.

Importante situar politicamente como os discursos no sentido da necessidade da construção das hidrelétricas na Amazônia foram colocados no cenário político. No ano de 
2000 a usina de Belo Monte foi incluída no plano plurianual 2000-2003 e apresentado ao Congresso. Nesse interím, o apagão ocorrido em 2001, durante o governo de Fernando Henrique, traz à lume a celeuma acerca da insuficiência energética do país. No bojo das eleições de 2002, Fernando Henrique apoia a construção da hidrelétrica de Belo Monte, e na outra ponta, Lula se coloca desfavorável às construções de hidrelétricas na Amazônia.

Em 2007, com Projeto de Aceleração do Crescimento (PAC), traz como resposta para a crise energética a implementação das usinas hidrelétricas de Belo Monte, Santo Antônio e Jirau, responsabilizando-as por quase um terço da energia do Projeto Energético do país. Esse cenário se molda ao arrepio das leis, sem o devido licenciamento ambiental, e as referidas usinas já são objeto de leilão. Nesse interregno, muitos conflitos foram verificados, dentre eles, manifestações de indígenas e ribeirinhos, greves de trabalhadores nos canteiros de obras, ações judiciais propostas pelo Ministério Público Federal em atuação conjunta com os Ministérios Públicos dos Estados, que, buscaram impedir a continuidade da construção das mesmas, porém sem sucesso.

Inúmeras violações de direitos foram observadas ao longo da realização das referidas obras, danos que se protraem no tempo e intensificam processos de desigualdes sociais existentes, bem como uma forçada imposição de modo de vida, produção e aniquilação de culturas entre outros. Santo Antônio e Jirau são exemplos que que nada do que foi prometido como compensação foi cumprido. Deslocamento forçado dos moradores das margens dos rios para outros locais onde sequer havia condições de manterem-se pelo modo de produção ao qual eram acostumados, eis que suas atividades são ligadas à pesca e à agricultura, não se podendo esquecer das indenizações que de maneira alguma poderiam compensar às perdas sofridas.

Falta de acesso aos serviços públicos, como escola, postos de saúde, saneamento básico e até mesmo moradia digna, aumento da prostituição infantil, aumento da criminalidade, insegurança, entre outras violações de direitos humanos fundamentais. E em maior proporção, a cheia do Rio Madeira, a maior do Estado de Rondônia, registrando 19,74 metros acima do nível normal, que embora conflitem visões técnicas controversas acerca da relação de causalidade entre as construção das hidrelétricas e a cheia do rio, a situação fática responde por si. Onde estaria o Direito diante desse contexto? Estaria o Direito à serviço da sustentabilidade? Sustentabilidade de quê e de quem? Para quem? 
Nesse momento, cabe situar as dimensões da sustentabilidade e verificar se o Direito as tem considerado na sua atuação em matéria ambiental. Consoante leciona Juarez de Freitas, a sustentabilidade é pluridimensional, dotada de riqueza poliédrica. Suas dimensões, social, ética, jurídico-política, econômica e ambiental se complementam e fazem da sustentabilidade um princípio, muito mais que constitucional, mas sobretudo um princípio que deve ser elevado à categoria de jus conjens, apto a combater da lógica hegemônica que tem sido determinada pelo capital financeiro face à natureza.

As violações de direitos que decorrem dessa dinâmica devastadora do meio ambiente, que assola comunidades e seus conhecimentos tradicionais, acarreta riscos para as gerações presentes e futuras. Essa indiferença aponta o ator econômico como deveras hegemônico, sobretudo porque se serve do cumprimento da legalidade como forma de legitimação do que é socialmente reprovável.

A lógica se inverte, como apontado por Oliveira (2005) quando salienta que a estratégia é discutir a "questão ambiental" como percalço do Capitalismo, e nessa perspectiva, técnicas e dispositivos são vistos como soluções, ou seja, a cartilha do pensamento dominante se vale da própria torpeza para apontar saídas para um labirinto que ele mesmo, o sistema, se colocou.

Nessa toada, como acertadamente alude Oliveira (2005), a técnica e a ciência insiste em subjugar a natureza em prol dos grandes lucros, dando continuidade a um ciclo vicioso que em busca de um desenvolvimento a qualquer custo, adjetiva como sustentável, práticas e receitas que desconsideram as peculiaridades locais, contradições de ordem geopolítica e social dentre outros fatores, com o fito de adaptar os percalços colocados pela natureza na via de passagem do capital.

Importante salientar que essa rede de símbolos da qual se vale a ideologia a serviço do sistema capitalista utiliza-se de uma coerção por meio do convencimento, onde o Direito funciona como o regulador e guardião do modelo preconizado, fazendo a devida separação dos indivíduos que se conformam ou não ao padrão. Trata-se em verdade de uma reprodução social de adequação e conformidade aos valores e normas instituídos em favor da conservação, afastando assim qualquer possibilidade de transformação social, sobretudo porque a transformação retira a segurança da coerência e da continuidade (LAYRARQUES, 2003, p. 37-38). 
Denota-se que há uma ideologia que sustenta o plano jurídico-político, da mesma forma que há poderes que sustentam o Estado. A compreensão dos fundamentos mais profundos dos fenômenos sociais contemporâneos, aponta a ideologia como condutora de determinados processos de construção da norma, demonstrando porque as relações de poder que impõem o direito o constroem sob forma estatal. O jurídico e o estatal são manifestações decorrente de um poder que não se encontra apenas nas atribuições e competência que formalmente lhes foram conferidas, mas abrangem e habitam campos tão esparsos como as eestruturas de reprodução econômica, a força militar, o econômico, político, cultural entre outros. Perceber essas relações de poder retira a análise da confusão entre o jurídico e o estatal (MASCARO, 2013, p. 52-64).

Nesse sentido, questiona-se: qual a influência da ideologia do capital nas decisões judiciais em matéria ambiental? Denota-se que algumas decisões judiciais em matéria ambiental tem sido reflexos de uma reprodução ideológica de dominação social, que tem no Direito, por meio da aplicação das leis vigentes, seu instrumento de poder. Como visto no cenário brasileiro, complexos hidrelétricos tem sido implantados na região amazônica, contrariando não só os estudos de impacto ambiental e demais relatórios que demonstram a inviabilidade de tais obras, mas principalmente se sobrepondo a toda uma realidade social existente.

O desconhecimento do processo de constituição e significação dos símbolos retira a possibilidade de se chegar ao questionamento daquilo que emana dos poderes estabelecidos e as respostas por eles concedidas. Consoante aponta Campos (2011, p. 191) o sistema jurídico tem aparência de legalidade, ordem e justiça, porém algumas leis não levam em conta as desigualdades sociais, aliás pode inclusive, aumentar e alimentar essas desigualdades, na medida em que resta por encobrir contradições sociais e dominação política de segmentos sociais sobre outros.

Esse idealismo jurídico, tende a pensar o Direito com base em representações e não a partir da realidade dos fenômenos sociais. Reside aí, o descompasso entre Direito, ideologia e os anseios de bem comum da coletividade. E é inegável que o judiciário, mais especificamente a figura do juiz, não está imune à essas cargas valorativas e ideológicas (CAMPOS, 2011, p.196-197).

Os verdadeiros interesses atendidos e os direitos que são violados frente ao poder do capital no contexto da implantação das Hidrelétricas do Madeira e de Belo Monte, dentre 
outras formas de exploração dos recursos naturais no Brasil, demonstram que conforme observa criticamente Portanova (2000, p. 52-56), ao contrário do que deveria ocorrer, o Estado tem se comportado de modo a proteger os interesses dos dominantes (capital financeiro) em relação aos interesses dos dominados (sociobiodiversidade). E na mesma toada, o judiciário tem desempenhado seu mister de manutenção e consecução dos objetivos do Estado, reafirmando ser uma instância política e subsistema do sistema político global (CAMPOS, 2011, p.197-200).

Karl Marx em sua crítica à economia política, ressaltou que as:

... relações jurídicas, tais como formas de Estado, não podem ser compreendidas nem a partir de si mesmas, nem a partir do assim chamado desenvolvimento geral do espírito humano, mas, ao contrário, elas se enraízam nas relações materiais de vida. (MARX, 2002).

O confronto entre o Direito e a realidade, deve partir da constatação dos problemas que se colocam na sua aplicação, efetivação e deve visar a melhoria de vida da sociedade, partindo de uma visão crítica, pensando como as práticas jurídicas tem sido construídas e o papel que assumem da reprodução e transformação social. Se há ou não coerência entre as relações de desigualdade e as posturas teóricas hegemônicas. A teoria jurídica não mais dá conta de acobertar o abismo que separa o Direito da realidade e muito menos de que é o próprio Direito que acaba por ampliar esse abismo (MELO, 2009, p. 25-28).

A mercantilização crescente dos recursos naturais, bem como a transformação do homem em meio, instrumento ou mercadoria, acaba tendo o Direito como um legitimador, na medida em que a pergunta crítica que deve ser feita, não ecoa nas decisões em matéria ambiental, qual seja: a quem serve determinada norma e quais os interesses que ela de fato protege? Daí "a necessidade de colocar em xeque os limites das pretensas cientificidade e neutralidade jurídicas.” (MELO, 2009, p. 29-30).

No que cabe à abordagem do Direito Internacional, é consabido a vasta quantidade de normativas, tratados entre outros, que protegem o meio ambiente. Ressalte-se que, a questão ambiental deixa marcas e reflexos transfronteiriços, versam sobre relações translocalizadas e deve considerar a sociobiodiversidade um direito supranacional. A colocação do meio ambiente na esfera de proteção dos direitos humanos advém da perspectiva de que questões ligadas à proteção do meio ambiente não se limitam à poluição advinda da 
industrialização, eis que abarcam uma gama de direitos muito mais complexos, envolvendo todo o planeta.

Contudo, interessante analisar a dificuldade que os tribunais pátrios tem tido em aceitar aplicar e considerar decisões como da Corte Interamericana de Direitos Humanos, bem como recomendações e tratados relativos à proteção do meio ambiente. Nesse sentido, verifica-se que o controle de convencionalidade feito pelo Brasil, demonstra uma grande resistência em mediar conflitos ambientais transnacionais, eis que torna inexequível as normativas internacionais e as mantém no plano das recomendações (MAZZUOLLI, 2007, 169-194).

Essas contradições são percebidas também na política interna, externa e na aplicação das normas pelo agentes públicos. Veja-se que com relação ao Sistema Interamericano de Direitos Humanos, o Brasil, no que se refere à implantação das hidrelétricas, em específico a de Belo Monte, quatro dias após a Comissão Interamericana de Direitos Humanos outorgar a Medida Cautelar no $382 / 10$ em $1^{\circ}$ de abril de 2011, o Ministério das Relações Exteriores do Brasil, na pessoa do embaixador Antônio Patriota asseverou que "O Governo brasileiro considera as solicitações da CIDH precipitadas e injustificáveis" " Já no âmbito do Congresso Nacional, o Senador Flexa Ribeiro (PSDB-PA), presidente da subcomissão de acompanhamento das obras de Belo Monte, declarou: "É um absurdo. A OEA está entrando numa questão que diz respeito à soberania do Brasil, não há sentido"2

Reação semelhante foi a da Secretária de Direitos Humanos, Ministra Maria do Rosário, quando entendeu que "houve uma certa agilização desmedida da comissão de direitos humanos neste terreno"3 e de maneira muito mais severa, pronunciou o Ministro de Minas e Energia, Edison Lobão, quando afirmou que "o governo brasileiro não precisa de mais fiscais para decidir o que deve ou não ser feito para aumentar a capacidade de geração de

\footnotetext{
${ }^{1}$ Brasil. Ministério das Relações Exteriores. Solicitação da Comissão Interamericana de Direitos Humanos (CIDH) da OEA. Nota à imprensa nº 142. Brasília, 5 de abril de 2011. Disponível em http://www.itamaraty.gov. br/sala-de-imprensa/notas-a-imprensa/solicitacao-da-comissao-interamericanade-direitos-humanos-cidh-da-oea ${ }^{2}$ Mariana Oliveira, "Posição da OEA sobre Belo Monte é 'absurda', diz subcomissão do Senado", G1, Brasília, 05/04/2011, disponível em: http://g1.globo.com/politica/noticia/2011/04/posicao-da-oea-sobrebelo-monte-eabsurda-diz-subcomissao-do-senado.html

${ }^{3}$ Rádio Câmara, Maria do Rosário critica decisão da OEA de pedir suspensão do processo de licenciamento de Belo Monte (01'48"), Brasília, 06 de abril 2011. Áudio disponível em: http://www2.camara.leg.br/ camaranoticias/radio/materias/ULTIMAS-NOTICIAS/395382-MARIA-DOROS\%C3\%81RIOCRITICADECIS C3\% $83^{\circ}$-DA-OEA-DE-PEDIR-SUSPENS\%C3\%83O-DOPROCESSO-DE-LICENCIAMENTO-DE-BELOMO NTE-(01'48\%22).html.
} 
energia elétrica no país"4. Esses discursos, claramente imbuídos de uma carga ideológica, permearam as manifestações governamentais, bem como decisões e entendimentos judiciais, sob a bandeira de proteção contra a interferência na soberania e na economia do Brasil.

O contexto do discurso que legitimou a construção das hidrelétricas do Madeira e a de Belo Monte, bem como de outras formas de legitimação da esploração dos recursos naturais na Amazônia, tem causado uma convulsão nas bases democráticas trazidas pela $\mathrm{CF} / 88$. Isso porque vários direitos foram flagrantemente violados, como por exemplo a não oitivas dos indígenas e população ribeirinhas no âmbito das audiência públicas e total desrespeito aos direitos fundamentais dos mesmos; a ostensiva atuação da Força Nacional de Segurança Pública nas localidades das obras; falta de diálogo com os movimentos sociais e Organizações Não-Governamentais; uso da Suspensão de Liminar como instrumento jurídico à serviço do capital, bem como total desconsideração pelos Sistema Interamericano de Direitos Humanos.

Outro ponto relevante a ser mencionado, refere-se a debilidade do accountability horizontal de órgãos como a FUNAI e IBAMA, que em detrimento dos interesses de seus legítimos representados, se coadunam com os interesses do capital, da mesma maneira que as instâncias jurídicas restam por refletir o desiderato político. Não há como negar que o modelo de desenvolvimento energético da exploração dos recursos hidíricos na Amazônia enaltece o interesse e estabilização econômica, utilizando-se para isso da exploração dos recursos naturais em detrimento de outros interesses e direitos não só ao arrepio da lei, mas muitas vezes sendo a própria lei o instrumento facilitador das referidas violações.

Cabe agora, verificar como a política externa brasileira, enquanto variável dependente, influencia nesse cenário de mercantilização da Amazônia e como tem se dado sua atuação nos útimos anos.

\subsection{Política Externa (consequente - variável dependente).}

Nesse momento, cumpre esclarecer se a política externa brasileira traduz uma política de Estado consolidada no que toca às questões ambientais ou se oscila seus interesses de acordo com as políticas de governo e a conjuntura internacional, bem como se ela, como variável dependente que é, atua a serviço da sustentabilidade.

\footnotetext{
${ }^{4}$ Nielmar de Oliveira, "Ministro de Minas e Energia critica postura da OEA sobre Belo Monte", Carta Capital, 07 de abril de 2011. Disponível em: http://www.cartacapital.com.br/politica/lobao-critica-oeapor-ingerencia-embelo-monte.
} 
Como aludido anteriormente, uma das características apresentadas pelo Brasil em matéria ambiental inclusive, é a utilização do princípio da soberania como escudo justificador da não aceitação de controles internacionais sobre as violações internas de direitos humanos fundamentais. Por outro lado, observa-se que a política externa brasileira possui alguns princípios consolidados, dentre eles, o da valorização do multilateralismo, respeito à soberania, mas também é patente que é a agenda política que determina a defesa ou não de determinadas questões.

O Brasil, desde o governo Lula vem tentando apresentar uma nova postura acerca das questões ambientais internacionais, tendo por características uma maior assertividade e a atuação como uma espécie de "líder conciliador" entre as demandas do Norte desenvolvido e do Sul em desenvolvimento. Isso decorre em função da diferença de perspectivas entre países em situações socioeconômicas distintas, eis que de um lado, os países desenvolvidos apontavam medidas preventivas imediatas a fim de evitar desastres naturais, enquanto que, no entendimento dos países em desenvolvimento, algumas medidas poderiam encarecer, bem como atrasar mais ainda seu desenvolvimento. Saliente-se ainda, que não há uma unanimidade quanto a gravidade dos problemas ambientais, os objetivos são divergentes e a cooperação internacional em termos de proteção ambiental se torna cada vez mais difícil (PASSOS, 2009).

Essencial salientar que ao falar-se em política externa, necessário ter um panorama das condicionantes ditadas pelos fatores externos e internos e, na questão ambiental, isso não é diferente. Com a crise econômica de 2008, consequência do neoliberalismo, verificou-se a urgência de alternativas mais sustentáveis ambiental e economicamente. A postura dos países em geral, como a do Brasil, foi ditada pela conjuntura doméstica e também a agenda internacional, dentre esses fatores teve-se nos últimos 23 anos, conferências mundiais acerca da questão ambiental que se deram em momentos qualitativamente opostos. A Rio-92 deu-se em um cenário de abertura econômica e mitigação da função dirigente do Estado. A Rio+20 teve como cenário um novo comportamento do Estado, caracterizado pelo aumento e redefinição desse papel (OLIVEIRA, 2014).

Ressalte-se que no contexto brasileiro, especificamente em 1992, vigorava o ápice da desconstrução do paradigma desenvolvimentista que até então era o fio condutor da política externa do Brasil. A agenda ambiental, até o fim do período do regime militar, era permeada por questões inegociáveis na seara internacional, eis que faziam parte de um discurso de 
afirmação da soberania nacional e que se legitimava pela defesa do direito dos países do terceiro-mundo ao desenvolvimento (SENNES, 2003).

A busca por um outro modelo de crescimento interno fazia-se necessária, uma vez que de substituição de importações estava esgotado, o que restou por fomentar um novo debate acerca da postura brasileira diante da possibilidade de uma inserção internacional tendo findado o regime militar e o processo de redemocratização (HIRST; PINHEIRO, 1995).

O neoliberalismo passou a conduzir a política externa brasileira e o governo Collor, o fez também na seara interna, colocando em prática a liberalização comercial, as privatizações e a mitigação da função estatal, e essa nova postura também permeou a seara ambiental. Assim, buscou-se atrair capitais estrangeiros, bem como houve uma busca incessante de apoio político dos países desenvolvidos, sobretudo dos Estados Unidos.

Tratava-se portanto de um verdadeiro alinhamento ao Norte, com o objetivo de que o Brasil ocupasse uma posição de destaque na construção da nova estrutura institucional internacional. Porém, cumpre mencionar, que esse alinhamento não foi adotado pelo corpo diplomático brasileiro, eis que optou por traçar uma estratégia de política externa apartada da ideologia política do grupo governante, pois prezava pelo multilateralismo e o respeito à soberania, tanto é que na Rio-92, passou a se comportar de forma autonomista, rechaçando as influências externas que refletissem qualquer ingerência no tocante aos recursos naturais e que pudessem conflitar com os interesses e fins dispostos nacionalmente, preservando porém o diálogo e a cooperação com relação aos países industrializados (FARIA, 2012).

O interesse do Brasil em atuar proativamente em matéria ambiental, se deu a partir de 2002, período marcado pelo fortalecimento do Estado Nacional, seguido pouco depois da chegada do Partido dos Trabalhadores à presidência, a Rio+20 e por consequência, algumas políticas para a redução dos níveis de desmatamento na Amazônia, bem como incentivos à produção de biocombustíveis. A reboque obteve-se a aprovação da lei 12.187 (Política Nacional de Mudanças Climáticas), como compromisso político de redução de emissões, firmado nos marcos da Conferência das Nações Unidas sobre Mudança do Clima (COP-15) (ESTEVO, 2011)

Importante mencionar que a agenda ambiental brasileira teve foi prioridade no período entre 2009 e início de 2010, isto é, ainda no governo Lula, onde houve o fortalecimento de um movimento de cunho ambientalista no governo após a candidatura de Marina Silva à presidência da República. Por outro lado, já no governo Dilma Rousseff, 
agenda ambiental perdeu um pouco sua prioridade, mesmo tendo sido o período em que Brasil sediou a Rio+20. (FRANCHINI; VIOLA, 2012).

Para compreender a preocupação da política externa brasileira com a questão ambiental, importante se reportar a postura do Brasil ao se candidatar para sediar a Rio-92. Foi lá que, em discurso na Assembleia Geral da ONU em dezembro de 1988, o embaixador brasileiro Paulo Nogueira Batista, aponta a relevância de incorporar as questões sobre as desigualdades entre os países do Norte e do Sul ao debate ambiental, bem como garantir a instalação de mecanismos que permitam diminuir esta desigualdade (BATISTA, 1988, p.11).

Assim, o referido embaixador, assim esclarece:

[...] o meio ambiente é um patrimônio nacional cuja proteção é de responsabilidade do governo brasileiro em todos os níveis. Em capítulo especial sobre as questões ambientais, a Constituição coloca a Floresta Amazônica e o Pantanal mato-grossense sob proteção especial do Estado. [...] Em desenvolver a sua economia, o Brasil está disposto a fazer uso das mais modernas tecnologias disponíveis. Com isso, estaria evitando cometer os mesmos erros que as nações mais desenvolvidas cometeram, os quais causaram grande dano ao seu próprio meio ambiente e que vêm esgotando os recursos naturais mundiais de forma desproporcional. [...] Conhecimento tecnológico e, em especial, acesso a recursos financeiros adicionais poderiam desempenhar um papel significativo no desenvolvimento nacional. (BATISTA, 1988, p.10-11)

Denota-se nesse ponto, que a postura do Brasil refletida nas palavras do embaixador retromencionado, aponta para um enaltecimento da soberania, acompanhada da cooperação, destacando-se como líder regional, que embora conciliador, a política externa brasileira deixa claro que pretende manter a soberania sobre os seus recursos naturais.

Nesse sentido, o princípio da soberania ocupa um lugar especial no cenário geopolítico e geoestratégico para o política externa brasileira, pois como alerta Maria Beatriz Oliveira da Silva, no que toca aos recursos naturais os quais o Brasil possui, e na esteira de serem considerados "bem comum da humanidade", urge saber: qual seu real sentido no domínio jurídico-ambiental desse termo, “diante da soberania (ambiental) dos estados (especialmente os “do lado de cá”)?” A referida autora esclarece que é necessário "reafirmar a 
soberania (ambiental) dos Estados sem negar a importância simbólica da luta pelo meio ambiente como um Bem comum da humanidade - para além do patrimônio comum.”

Esse o posicionamento do governo brasileiro até os dias atuais, não havendo porém um maior movimento no sentido de tratar a Amazônia e seus recursos naturais sob o prisma da defesa da soberania ambiental de forma a reconhecer sua posição geoestratégica e geopolítica.

\section{3 - CONSIDERAÇÕES FINAIS}

O presente artigo se propôs a analisar o processo ideológico de mercantilização da amazônia e como o direito e política externa podem ou não atuar a serviço da sustentabilidade.

Verificou-se que embora a sustentabilidade tenha feições multidimensionais e de inteligência sistêmica, a devida discussão acerca de seu conceito não tem sido alargada não só no âmbito da compreensão jurídica, mas também não tem ocupado espaço no âmbito da política externa, embora o meio ambiente seja uma das bandeiras mais levantadas pelo Brasil no cenário internacional.

A política externa brasileira apresenta-se como uma política de Estado consolidada no que toca às questões ambientais, porém seus interesses nos últimos anos tem oscilado de acordo com as políticas de governo e a conjuntura internacional.

O tratamento específico e concatenado esperado muitas vezes é decorrência lógica dos interesses do capital e se choca à almejada sustentabilidade, eis que as soluções negociadas que envolvem aspectos econômicos, políticos, tecnológicos e comportamentais, encontram correlação com os diferenciais de poder e as assimetrias que marcam o sistema internacional.

Nessa esteira, verifica-se que o Brasil passou de um período de postura confrontacionista para adotar uma posição marcada pela assertividade, pois buscou defender os interesses particulares dos países em desenvolvimento sem adotar uma postura radical, por meio da cooperação, funcionando como canal de comunicação com os países desenvolvidos do Norte e campo fértil de acordos entre as diversas nações.

Contudo, trazendo para o plano das grandes obras hidrelétricas realizadas na Amazônia e as demais formas de exploração dos recursos naturais, é inegável que a situação do Brasil é de verdadeiro entreguismo de suas riquezas, bem como violações de direitos 
fundamentais decorrente do fato de que o poder de decisão passou para as mãos de grandes grupos financeiros e não só o Direito mas também a política externa brasileira tem sido instrumento a serviço da ideologia do capital como modelo de desenvolvimento único e necessário.

\section{REFERÊNCIAS}

BASTOS JUNIOR, Ronaldo Carvalho. A influência do ideológico no jurídico: para uma teoria marxista do direito a partir do conceito negativo de ideologia. Revista Jurídica DIREITO \& REALIDADE, Monte Carmelo-MG, V.01, n.01, Jan./Jun. 2011.

CAMPOS, Walter de Oliveira. DIREITO E IDEOLOGIA. Revista Argumenta, Jacarezinho - PR, n. 14, p. 187-204, Fev. 2013. ISSN 2317-3882. Disponível em:

<http://seer.uenp.edu.br/index.php/argumenta/article/view/191>. Acesso em: 13 Dez. 2015.

ESTEVO, Jefferson dos Santos. Política externa brasileira para mudanças climáticas.. In: $3^{\circ}$ ENCONTRO NACIONAL ABRI 2011, 3., 2011, São Paulo. Proceedings online...

Associação Brasileira de Relações Internacionais, Instituto de Relações Internacionais - USP, Disponível em:

<http://www.proceedings.scielo.br/scielo.php?script=sci_arttext\&pid=MSC00000001220110 00200033\&lng=en\&nrm=abn>. Acesso em 17 dez. 2015.

FARIA, Celso A. P. O Itamaraty e a política externa brasileira: do insulamento à busca de coordenação dos atores governamentais e de cooperação com os agentes societários. Contexto internacional, v.34, n.1, Rio de Janeiro, 2012.

FOLADORI, Guillermo. LIMITES DO DESENVOLVIMENTO SUSTENTÁVEL.

Tradução: Marise Manoel. Campinas. SP. Editora Unicamp. 2001.

FRANCHINI, Matías; VIOLA, Eduardo. Sistema internacional de hegemonia

conservadora: o fracasso da Rio +20 na governança dos limites planetários. Ambiente e Sociedade, São Paulo, v. 15, n. 3, p. 01-18, Dec. 2012.

FREITAS, Juarez. SUSTENTABILIDADE: Direito ou Futuro, Belo Horizonte: Forum, 2012.

GARRAD, Greg. Ecocrítica, Brasília: Editora UnB, 2006.

HARVEY. David. Para entender O Capital: livro 1. Tradução de Rubens Enderle. São Paulo: Boitempo, 2013.

HIRST, Mônica; PINHEIRO, Letícia. A política externa do Brasil em dois tempos. RBPI. Brasília: Ano 38, n. 01, p. 5-23, 1995.

LAYRARQUES, Phillippe Pomier. A natureza da ideologia e a ideologia da natureza: elementos para uma sociologia da educação ambiental, Campinas, SP, 2003. 
MARX, Karl. O capital: crítica da economia política: Livro primeiro: o processo de produção do capital. Tradução de Reginaldo Sant'Anna. 19. ed. Rio de Janeiro: Civilização brasileira, 2002.

MASCARO, Alysson. Pensamento jurídico contemporâneo (capítulo 5 do Livro Introdução ao Estudo do Direito, São Paulo Atlas, 2013).

MAZZUOLI, Valerio de Oliveira. A proteção internacional dos Direitos Humanos e o Direito Internacional do meio ambiente. Revista Amazônia Legal de estudos sociojurídicos-ambientais. Cuiabá. Ano 1, p. 169-196, jan-jun. 2007.

MELO, Tarso de. Direito e Ideologia: um estudo a partir da função da propriedade rural. São Paulo. Expressão Popular, 2009.

MENDONÇA, Ricardo. João Paulo Capobianco: "O governo é pré-histórico na questão ambiental" (íntegra). Revista Época. On-line, 13 abr. 2012. Disponível em: $<$ http://revistaepoca.globo.com/tempo/noticia/2012/04/joao-paulo-capobianco-o-governo-epre-historico-na-questao-ambiental-integra.html>. Acesso em: 20 dez. 2015

OLIVEIRA Leandro Dias de. A Ideologia do Desenvolvimento Sustentável: notas para reflexão Revista Tamoias- Julho / Dezembro 2005, Ano II, nº2.

OLIVEIRA, Tássia C.; RIBEIRO, Renata A. Política Externa Brasileira na Construção da Ordem Ambiental Internacional: Desenvolvimento com Sustentabilidade. IX Encontro da ABCP, 04 a 07 de agosto de 2014, Brasília - DF, 2014.

PASSOS, Priscila Nogueira C. A Conferência de Estocolmo como Ponto de Partida para a Proteção Internacional do Meio Ambiente. Direitos Fundamentais e Democracia, v. 8, 2009.

SILVA, Maria Beatriz Oliveira da Silva. MOTA, Luiza Rosso. A soberania (ambiental) do "lado de cá"frente ao meio ambiente como patrimônio comum da humanidade. In Soberania e Meio Ambiente: A soberania ambiental vista do lado de cá. 1 ed. Curitiba, PR: CRV, 2015.

SENNES, Ricardo. As mudanças na política externa brasileira nos anos 1980. Porto Alegre: Ed. UFRGS, 2003.

TENDLER, Silvio. Documentário: Encontro com Milton Santos ou O Mundo Global Visto do Lado de Cá, 2006.

VEIGA, José Eli da. SUSTENTABILIDADE: a legitimação de um novo valor, São Paulo: editora SENAC, 2010.

VIOLA, Eduardo. Os quatro grandes fracassos da Rio+20 e o conservadorismo do Brasil: depoimento. [2 de julho, 2012]. Disponível em:

<http://www.ihu.unisinos.br/entrevistas/511065-entrevista-especial-com-eduardo-viola〉.

Acesso em: 28 nov. 2015 